B. C. Мхитарян, Т. В. Сарычева. Исследование структуры занятости по видам экономической деятельности в Российской Федерации

УДК 331

DOI 10.18101/2304-4446-2019-2-31-50

\title{
ИССЛЕДОВАНИЕ СТРУКТУРЫ ЗАНЯТОСТИ ПО ВИДАМ ЭКОНОМИЧЕСКОЙ ДЕЯТЕЛЬНОСТИ В РОССИЙСКОЙ ФЕДЕРАЦИИ
}

\author{
(C) Мхитарян Владимир Сергеевич \\ доктор экономических наук, профессор, \\ Национальный исследовательский университет «Высшая школа экономики» \\ Россия, 101000, г. Москва, ул. Мясницкая, 20 \\ E-mail; vmkhitarian@hse.ru
}

\section{(C) Сарычева Татьяна Владимировна}

кандидат экономических наук, доцент, Марийский государственный университет

Россия, 424000, г. Йошкар-Ола, пл. Ленина, 1

E-mail: tvdolmatova@bk.ru

Формирование структуры занятости, адекватной выбранному курсу реформ, способствует устойчивому развитию экономики, является ключевым аспектом при анализе существующего рынка труда и неотъемлемой частью всего комплекса взаимосвязей экономического развития страны и ее регионов. Для успешного управления занятостью на федеральном и региональном уровнях требуется разработка статистического инструментария, позволяющего раскрыть количественные закономерности взаимосвязей показателей рынка труда, использование которого позволит повысить эффективность функционирования рынка труда и обоснованность принимаемых решений по вопросам занятости с учетом видов экономической деятельности. В статье предложен статистический инструментарий, основанный на использовании методов многомерного статистического анализа, эконометрического моделирования и прогнозирования, позволяющий проводить комплексный статистический анализ занятости по видам экономической деятельности на уровне страны, ее федеральных округов и регионов.

Ключевые слова: структура занятости; виды экономической деятельности; эконометрическое моделирование; эконометрическое прогнозирование.

\section{Для цитирования:}

Мхитарян В. С., Сарычева Т. В. Исследование структуры занятости по видам экономической деятельности в Российской Федерации // Вестник Бурятского государственного университета. Экономика и менеджмент. 2019. № 2. С. 31-50.

Введение. Экономическое развитие общества во многом определяет структуру занятости населения, при этом сбалансированность этой структуры способствует повышению эффективности использования человеческого капитала. Обоснованность мер в экономической и социальной политике, способных гарантировать прогрессивные изменения в структуре занятости, во многом зависит от точности оценки перспектив занятости на макро-, мезо- и микроуровне.

Методы и результаты исследования. Занятость и трансформация ее структуры - одни из важнейших процессов, протекающих на рынке труда [6]. Среднегодовая численность занятых в России за последние одиннадцать лет увеличилась на 1,6 млн человек (рис. 1). 


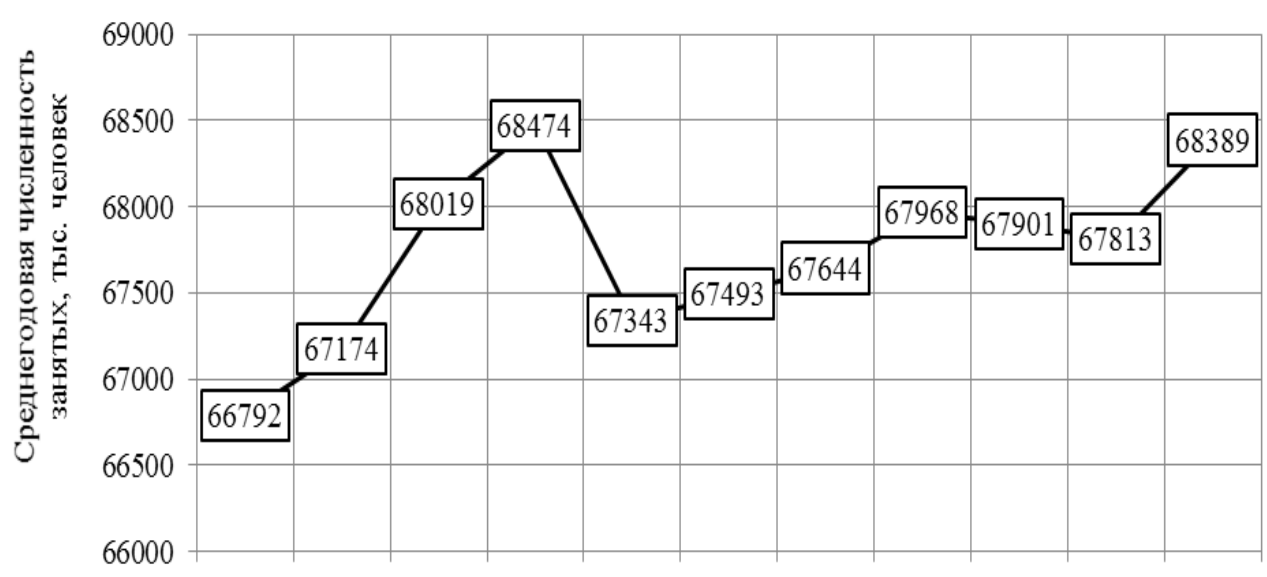

2005 г. 2006 г. 2007 г. 2008 г. 2009 г. 2010 г. 2011 г. 2012 г. 2013 г. 2014 г. 2015 г.

Рис. 1. Среднегодовая численность занятых в экономике РФ, 2005-2015 гг. (тыс. человек)

Визуальный анализ данных позволил выделить два этапа:

1-й этап: 2005-2008 гг., когда начался подъем экономики России и средний темп роста численности занятых составил $100,8 \%$. Рост численности занятых на первом этапе был характерен большинству видов деятельности. В данный период значительный рост численности занятых обеспечивали преимущественно два вида деятельности: оптовая и розничная торговля - 706 тыс. человек $(108,4 \%$ к 2005 г.), строительство - 315 (111,4\%). Наибольшими темпами в тот период росла занятость в финансовой сфере - 131,9\%, которая по абсолютному значению увеличилась на 274 тыс. человек. Численность занятых на первом этапе анализируемого временного интервала сокращалась только в пяти видах деятельности: в сельском хозяйстве, сферах обрабатывающего производства, добычи ископаемых и производства электроэнергии, газа и воды, а также в образовании. Данные виды экономической деятельности в совокупности потеряли более 1,11 млн человек.

2-й этап: 2009-2015 гг., восстановительный этап экономики после мирового финансового кризиса, когда темп роста среднегодовой численности занятых находился на уровне 100,3\%. Мировой финансовый кризис 2008 г. послужил причиной производственного спада во многих важных сферах деятельности. Кризисные явления сильнее всего сказались на обрабатывающих производствах, образовании, здравоохранении и предоставлении прочих услуг. В период 20092015 гг. здесь наблюдалось самое большое сокращение численности работников. При этом в образовании и предоставлении прочих услуг сокращение числа сотрудников компенсировалось их увеличением в докризисный период. В обрабатывающих производствах и здравоохранении сохранилась устойчивая тенденция сокращения численности занятых, причем скорость происходящих процессов выросла, то есть занятость за последние шесть лет здесь сокращалась еще большими темпами, чем в докризисный период.

В результате предварительного сравнительного анализа виды деятельности были разбиты на три группы. 
B. С. Мхитарян, Т. В. Сарычева. Исследование структуры занятости по видам экономической деятельности в Российской Федерации

В первую группу входят виды деятельности, где численность занятых постоянно снижается и не отвечает требованиям качества профессионального состава, что влечет за собой торможение развития данных направлений в перспективе. Вторая группа формируется из видов экономической деятельности, в которых динамика численности занятых в целом стабильна. Третью составили относительно благополучные виды деятельности, в которых позитивная динамика социально-экономических процессов способствует оптимальному соотношению количества и качества занятых, что создает благоприятные условия для их развития (табл. 1)

Таблица 1

Группировка видов экономической деятельности России по динамике численности занятого в них населения, 2005-2015 гг.

\begin{tabular}{|c|c|c|}
\hline $\begin{array}{c}\text { № } \\
\text { группы }\end{array}$ & $\begin{array}{c}\text { Характеристика } \\
\text { группы }\end{array}$ & Виды экономической деятельности \\
\hline 1 & $\begin{array}{c}\text { Сокращение } \\
\text { численности } \\
\text { занятых } \\
\end{array}$ & $\begin{array}{l}\text { Сельское хозяйство, охота и лесное хозяйство } \\
\text { Обрабатывающие производства } \\
\text { Образование }\end{array}$ \\
\hline 2 & $\begin{array}{c}\text { Стабильная } \\
\text { занятость }\end{array}$ & $\begin{array}{l}\text { Рыболовство, рыбоводство } \\
\text { Добыча полезных ископаемых } \\
\text { Производство и распределение электроэнергии, газа и воды } \\
\text { Предоставление прочих коммунальных, социальных и персональных } \\
\text { услуг } \\
\text { Гостиницы и рестораны } \\
\text { Транспорт и связь } \\
\text { Здравоохранение и предоставление социальных услуг }\end{array}$ \\
\hline 3 & $\begin{array}{c}\text { Рост численно- } \\
\text { сти занятых }\end{array}$ & $\begin{array}{l}\text { Финансовая деятельность } \\
\text { Государственное управление и обеспечение военной безопасности; } \\
\text { социальное страхование } \\
\text { Строительство } \\
\text { Операции с недвижимым имуществом, аренда и предоставление } \\
\text { услуг } \\
\text { Оптовая и розничная торговля; ремонт автотранспортных средств, } \\
\text { мотоциклов, бытовых изделий и предметов личного пользования }\end{array}$ \\
\hline
\end{tabular}

Анализ первой группы видов экономической деятельности показал, что в исследуемом периоде здесь наблюдался резонансный эффект: темп уменьшения занятых в прочих видах деятельности «отстает» от темпа уменьшения численности трудовых ресурсов. Для третьей группы видов деятельности также характерен резонансный эффект, но в данном случае значительный «чистый приток» трудовых ресурсов усиливается «притоком» из других видов деятельности экономики страны. Ко второй группе относятся виды экономической деятельности, не обнаружившие за анализируемый период какую-либо устойчивую тенденцию к изменению.

Для проведения структурно-динамического анализа занятости по видам экономической деятельности и расчета обобщающих показателей структурных изменений в занятости использовался интегральный коэффициент структурных различий — коэффициент Рябцева [4]. Сравнительный анализ цепных значений индекса Рябцева показал, что структура среднегодовой численности занятых по 
видам деятельности относительно устойчива в исследуемом периоде времени. Все смежные периоды интерпретировались как «тождественность структур», то есть процессы поэтапного изменения среднегодовой численности работников, занятых в отдельных видах деятельности, имеют схожую динамику, при этом с 2010 г. происходит замедление скорости происходящих изменений в структуре занятости (рис. 2).

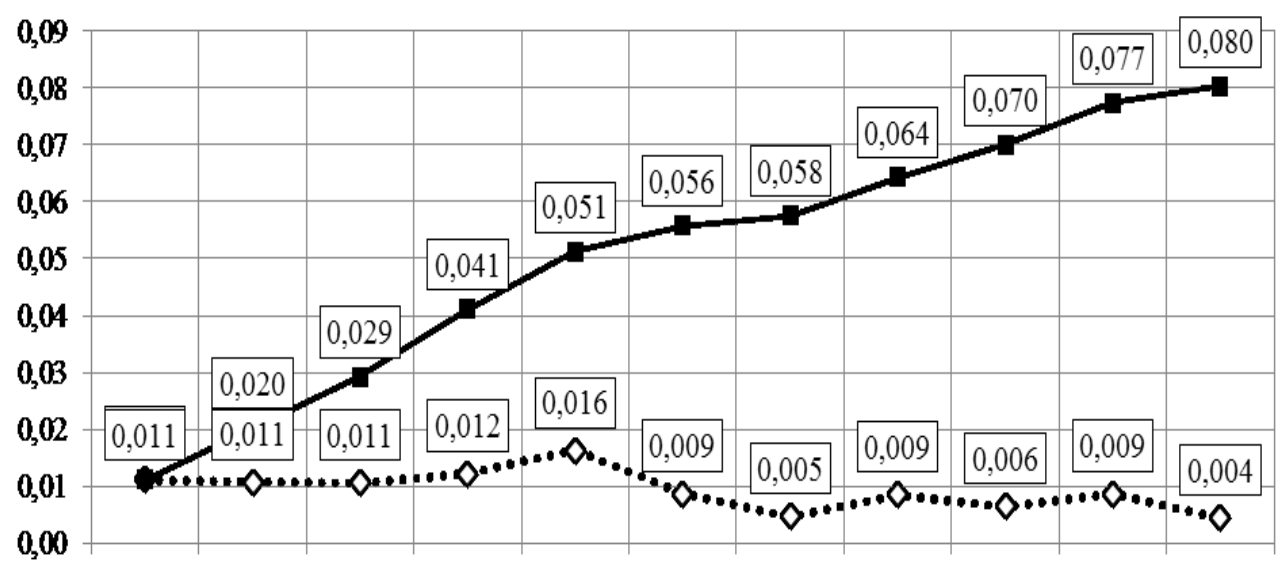

2005r. 2006r. 2007r. 2008r. 2009r. 2010r. 2011r. 2012r. 2013r. 2014r. 2015r.

\section{. ৯. - Цепные коэффициенты}

\section{$\rightarrow$ Базисные коэффициенты}

Рис. 2. Динамика индексов структурных различий в структуре занятости России по видам экономической деятельности, 2005-2015 гг.

Сопоставление базисных структурных коэффициентов показало, что в последние годы происходит трансформация системы занятости: к концу 2015 г. индекс Рябцева, рассчитанный относительно базисного 2005 г., перешел нижнюю границу интервала, который интерпретируется как низкий уровень различий, что связано с развитием сектора услуг, который постепенно поглощает потоки рабочей силы из производственных секторов экономики.

Прогнозирование величины базисных индексов структурных различий в занятости, выполненное на основе трендовых моделей, позволило сделать вывод, что лучшими аппроксимирующими свойствами обладает полиномиальная модель второго порядка:

$$
\begin{gathered}
\hat{y}_{t}=0,0004+0,0112 t-0,0004 t^{2} \\
t \text {-статистика: } \quad(11,1) \quad(-4,5) \\
R^{2}=0,99 ; F(2 ; 8)=457,6 ; D W=1,82 ; S . E=0,002 .
\end{gathered}
$$

Согласно прогнозу, выполненному по модели на 2016 и 2017 гг., можно предположить, что в ближайшее время структура занятости по видам экономической деятельности продолжит меняться, хоть и незначительно. Индекс структурных различий в 2016 г. составит 0,082, в 2017 г. - 0,084. 
B. С. Мхитарян, Т. В. Сарычева. Исследование структуры занятости по видам экономической деятельности в Российской Федерации

Для изучения воздействия факторов на динамику численности занятого населения по видам экономической деятельности и получения количественных оценок были построены эконометрические модели [7]. Информационную базу исследования составили помесячные данные по РФ за 2009-2015 гг.

В качестве результативных рассматривались показатели:

$y_{i t}$ - численность занятого населения на основной работе в $i$-м виде деятельности в момент времени $\boldsymbol{t}$ (человек).

В качестве объясняющих переменных в моделях рассматривались:

$x_{1}$ - отношение средней заработной платы работников к средней по экономике страны (ед.);

$x_{2}$ - численность работников, перед которыми организация имеет просроченную задолженность по заработной плате (чел.);

$x_{3}$ - темп роста/сокращения численности работников, перед которыми организация имеет просроченную задолженность по заработной плате (\%);

$x_{4}$ - объем просроченной задолженности по заработной плате работников (тыс. руб.);

$x_{5}$ - темп роста/сокращения объема просроченной задолженности по заработной плате работников (\%).

В качестве основных производственных показателей:

$x_{6}$ - индекс промышленного производства (\%);

$x_{7}$ - индекс интенсивности выпуска товаров и услуг (\%).

В качестве объясняющих также рассматривались демографические и временные характеристики:

$x_{8}$ - численность рабочей силы (тыс. чел.);

$x_{9}$ - численность трудоспособного населения (тыс. чел.);

$x_{10}$ - индекс сезонности;

$x_{11}$ - ранг месяца по числу занятых.

Уравнение регрессии численности занятых в сельском хозяйстве, важнейшего вида деятельности первичного сектора экономики, имеет вид:

$$
\begin{array}{cl} 
& \hat{y}_{C X, t}=-89,0-0,03 x_{2, t-1}+0,25 x_{8, t}+0,63 x_{10, t}+113,22 x_{11, t} \\
t \text {-статистика: } \quad(-3,2) \quad(2,8) \quad(3,7) \quad(14,1) \\
R^{2}=0,93 ; F(4 ; 54)=93,6 ; S . E=13,9 ; D W=2,19 .
\end{array}
$$

Регрессионная модель занятости в сельском хозяйстве показала, что занятость здесь в первую очередь зависит от численности работников, перед которыми организация имеет просроченную задолженность по заработной плате, и от численности экономически активного сельского населения. На занятость практически не влияет величина заработной платы. Для сельского населения занятость зависит лишь от наличия вакансий на рынке труда.

Прогнозная модель численности занятых в обрабатывающих производствах имеет вид АРПСС $(0,1,1)(1,0,0)$ (рис. 3). 


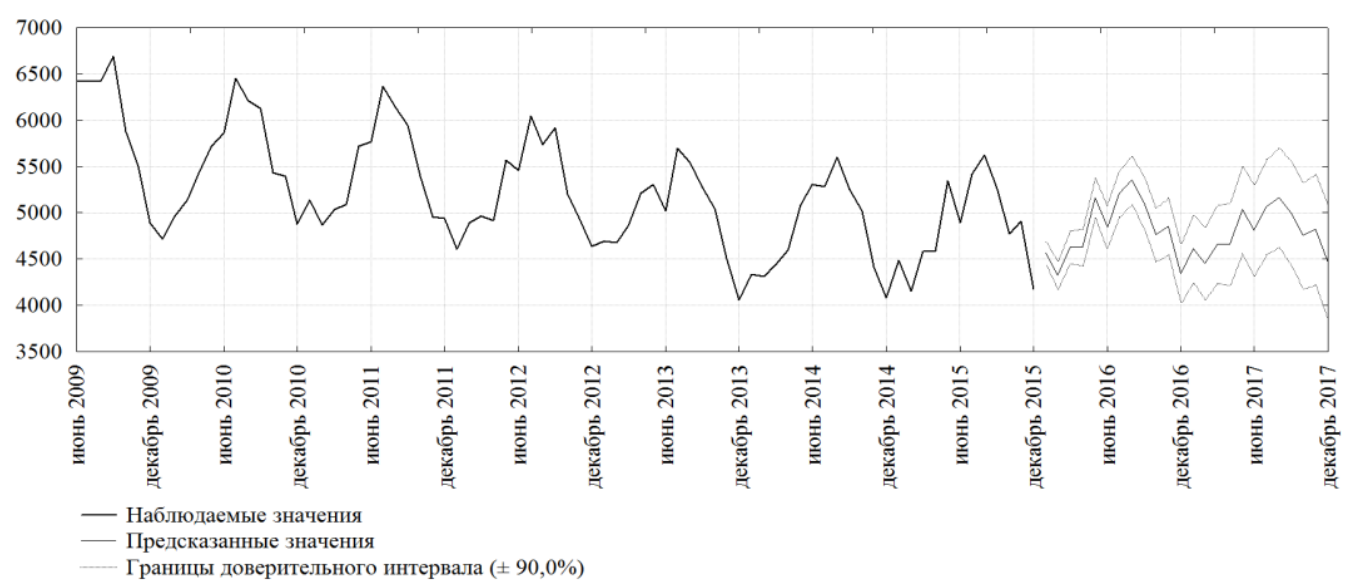

Рис. 3. Динамика численности занятых в сельском хозяйстве за 2009-2015 гг. с прогнозом на 2016-2017 гг. (тыс. чел.)

Согласно прогнозу, полученному по предложенной модели, максимальная численность занятых в сельском хозяйстве в 2016 г. будет наблюдаться в августе и составит 5353,9 тыс. человек. К концу года она несколько сократится и зафиксируется на отметке в 4347,7 тыс. человек. К концу 2017 г. численность занятых данным видом деятельности составит 4465,7 тыс. человек, что превышает значение показателя в аналогичный период 2015 г. на 6,9\%. Уравнение регрессии численности занятых в сфере обрабатывающих производств имеет вид:

$$
\begin{array}{r}
\hat{y}_{\text {OП }, t}=7268,5+54,3 x_{1, t-1}-4,2 x_{6, t-1}+0,25 x_{9, t}+4,0 x_{10, t}-0,47 y_{\text {TOP }, t} \\
t \text {-статистика: } \begin{array}{c}
(2,7) \quad(-3,5) \quad(2,1) \quad(2,2) \quad(-3,4) \\
R^{2}=0,96 ; F(5 ; 53)=254,4 ; S . E=7,6 ; D W=2,05
\end{array}
\end{array}
$$

Рост величины заработной платы в обрабатывающих производствах положительно влияет на численность занятого населения в данной сфере. Отрицательное влияние данных о численности населения, занятого в оптовой и розничной торговле, на результирующий показатель можно объяснить конкурентными преимуществами этого вида деятельности по сравнению с обрабатывающими производствами с точки зрения трудоустройства.

Прогнозные оценки численности занятых в обрабатывающих производствах, полученные по модели АРПСС $(0,1,1)(1,0,0)$, позволили сделать вывод о том, что численность занятых в данной сфере будет хоть и незначительно, но снижаться (рис. 4).

Уравнение регрессии численности занятых в оптовой и розничной торговле; ремонте автотранспортных средств, мотоциклов, бытовых изделий и предметов личного пользования, т. е. виде деятельности, определяющем развитие сферы рыночных услуг, имеет вид:

$$
\begin{gathered}
\hat{y}_{\text {TOP }, t}=-7465,5+20,8 x_{1, t-1}+12,6 x_{7, t-1}+0,06 x_{9, t}++132,0 x_{10, t}+0,001 x_{12, t} \\
t \text {-статистика: } \quad(2,0) \quad(2,5) \quad(2,9) \quad(4,6) \\
R^{2}=0,84 ; F(5 ; 53)=55,5 ; S . E=11,2 ; D W=1,95
\end{gathered}
$$


B. С. Мхитарян, Т. В. Сарычева. Исследование структуры занятости по видам экономической деятельности в Российской Федерации

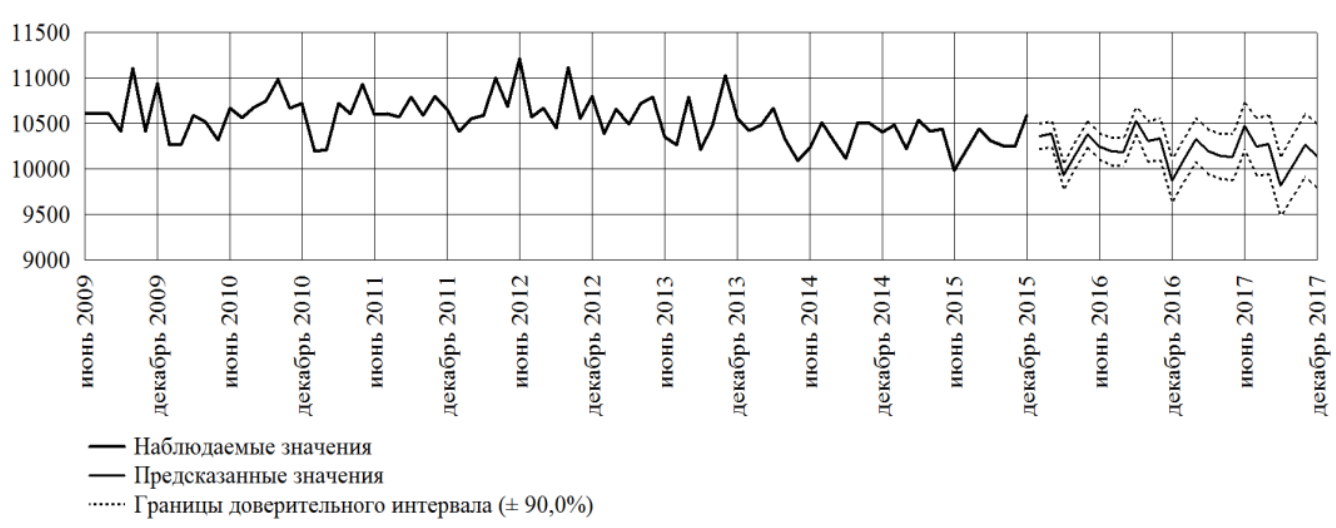

Рис. 4. Динамика численности занятых в обрабатывающих производствах России за 2009-2015 гг. с прогнозом на 2016-2017 гг. (тыс. чел.)

Значимыми объясняющими переменными, оказывающими влияние на численность занятых в сфере оптовой и розничной торговли, являются численность населения в трудоспособном возрасте и индекс сезонности, а также заработная плата и индекс интенсивности выпуска товаров и услуг.

Прогнозирование численности занятых в оптовой и розничной торговле; ремонте автотранспортных средств, мотоциклов, бытовых изделий и предметов личного пользования (рис. 5) осуществлялось на основе модели АРПСС $(0,1,1)(1,0,1)$, параметры которой статистически значимы.

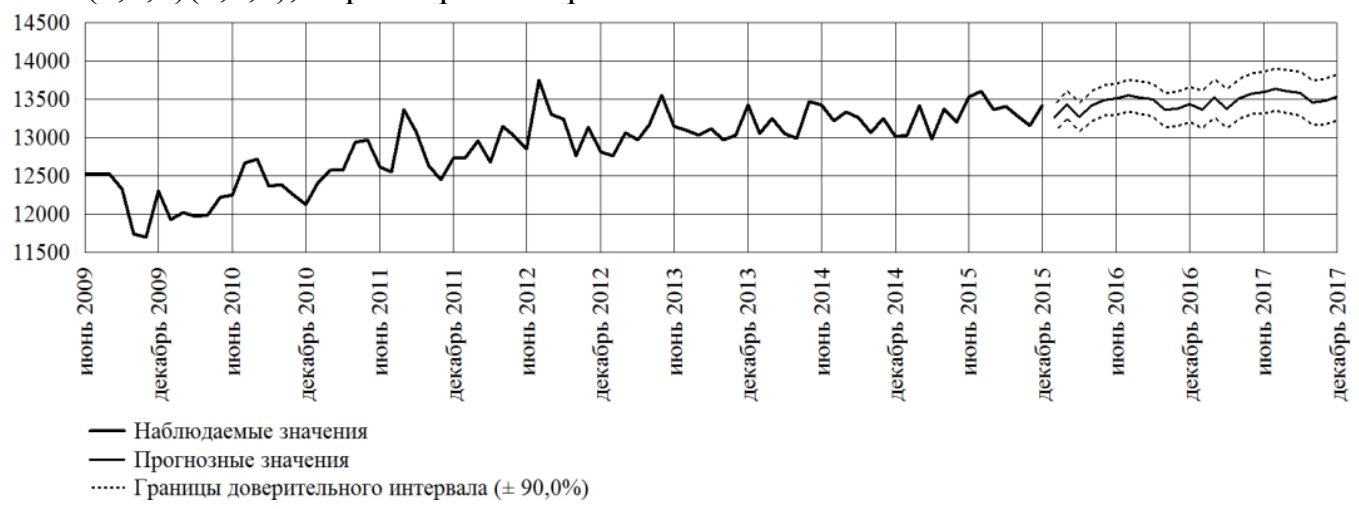

Рис. 5. Динамика численности занятых в оптовой и розничной торговле России за 2009-2015 гг. с прогнозом на 2016-2017 гг. (тыс. чел.)

Численность занятых в торговой сфере в декабре 2016 г. составила 13175,9 тыс. чел. Ошибка прогноза, выполненного по предложенной модели, составила $2,0 \%$. В перспективе численность населения, занятого в оптовой и розничной торговле, продолжит постепенно увеличиваться, поглощая трудовые ресурсы из сферы обрабатывающих производств и сельского хозяйства, и к концу 2017 г. достигнет 13533,2 тыс. чел.

Согласно моделям будет продолжаться некоторая трансформация структуры занятости по видам экономической деятельности: численность населения, занятого в оптовой и розничной торговле, будет постепенно увеличиваться, поглощая 
потоки трудовых ресурсов из сферы обрабатывающих производств и сельского хозяйства.

Для выявления асимметрии в региональной структуре занятости по видам экономической деятельности и дифференциации регионов по развитию секторов экономики была проведена типологизация региональных рынков труда. На первом этапе были выделены две группы регионов: специализированная и сервисная.

К сервисной группе были отнесены те регионы, в которых доля занятых в третичном секторе экономики превышает или сопоставима с долей занятых в третичном секторе по округу в целом; к специализированной - те регионы, в которых коэффициент локализации, рассчитанный для совокупности видов деятельности, относящихся к первичному и вторичному секторам экономики, был больше 1. Далее из группы специализированных регионов выделялись агропромышленные, индустриальные и смешанные регионы. Те из них, где индекс локализации больше 1 для видов деятельности первичного сектора экономики и меньше 1 для вторичного, были отнесены к агропромышленным. Регионы, которые характеризовались индексом локализации, имеющим значение меньше 1 для первичного сектора экономики и больше 1 для вторичного, были отнесены к индустриальным. Регионы с индексами локализации больше единицы и для первичного, и для вторичного секторов экономики были отнесены к смешанным. Таким образом, все регионы Российской Федерации были разбиты на 4 группы.

В группе сервисных оказались 22 региона. Интересно отметить, что только два из них относятся к Центральному федеральному округу: Московская область и г. Москва. К группе агропромышленных регионов был отнесен 31 регион. К группе индустриальных - только 8 регионов, при этом четыре федеральных округа вообще не были представлены в данной группе, что свидетельствует об отсутствии индустриальных регионов-лидеров в Северо-Западном, Южном, Дальневосточном и Крымском федеральных округах. Группа регионов, идентифицируемых как смешанные, была представлена 24 регионами Российской Федерации.

Сложившаяся видовая структура занятости населения отражает накопленные диспропорции. Подходы и выбор конкретных мер региональной политики и стратегий развития регионов (при общности и единстве целей) должны учитывать сложившуюся ситуацию на региональных рынках труда и их причины, особенно в тех случаях, когда речь идет о финансовой поддержке тех или иных территорий. Выходом может служить идея одновременного учета единства и различий в развитии территорий, методически предваренная грамотной их типологизацией, позволяющей выделить однородные территориальные образования.

Для определения доминирующего типа рынка труда в 85 субъектах Российской Федерации в 2015 г. использовались статистические данные о структуре занятости по видам экономической деятельности в региональном разрезе, а именно рассчитаны суммарные долевые пропорции вклада видов деятельности, условно отнесенных к разным типам рынков труда в общий размер среднегодовой численности занятых:

$x_{1}$ - вклад видов экономической деятельности, относящихся к смешанному рынку труда, в общий объем занятости региона, \%; 
B. C. Мхитарян, Т. В. Сарычева. Исследование структуры занятости по видам экономической деятельности в Российской Федерации

$X_{2}$ - вклад видов экономической деятельности, относящихся к внешнему рынку труда, в общий объем занятости региона, \%;

$X_{3}$ — вклад видов экономической деятельности, относящихся к внутреннему рынку труда, в общий объем занятости региона, \%.

Для лучшего понимания тенденций тяготения субъектов Российской Федерации к определенному типу рынка труда — внешнему или внутреннему, было проведено исследование, основанное на анализе характеристик, отражающих внутреннюю или внешнюю направленность региональных рынков труда:

$X_{4}$ - уровень безработицы, \%;

$X_{5}$ - доля занятых на малых предприятиях, \%;

$X_{6}$ - потребность в работниках, заявленная организациями в органы государственной службы занятости, в общей численности занятых, \%;

$X_{7}$ - средняя продолжительность поиска работы безработными, мес.;

$X_{8}$ - удельный вес безработных, ищущих работу больше года, \%.

С помощью кластерного анализа регионы России были разбиты по ориентированности на внешний, внутренний и смешанный рынки труда. Сопоставление двух видов кластеризации позволило определить, что на смешанный рынок труда одновременно и по структуре занятости по видам деятельности, и по характеристикам регионального рынка труда ориентирован только один регион - Еврейская автономная область.

На внешний рынок труда одновременно по структуре занятости и по характеристикам рынка труда ориентированы 10 регионов. Эти регионы нуждаются в реализации дополнительных программ профессиональной подготовки и переподготовки работников, в совершенствовании системы профессионального образования, учитывающей потребности рынка труда и специализацию регионов.

Сложность и неоднозначность ситуации с занятостью в нашей стране делают необходимым поиск путей ее развития на уровне отдельных регионов. Эффективность структуры занятости по видам деятельности рассматривалась через призму производственного и финансового критериев, а также через возможность удовлетворения социальных потребностей населения региона. Структура занятости региона считалась эффективной с точки зрения производственного критерия, если она характеризовалась минимальными удельными затратами ресурсов на единицу выпуска. Финансово эффективной структурой занятости признавалась та, которая максимально аккумулировала финансовые ресурсы региона. Социальная направленность исследовалась с точки зрения покупательной способности населения [2].

Сопоставление результатов классификации по трем группам показателей позволило сделать вывод о том, что только три региона характеризуются высокими показателями эффективности структуры занятости по всем трем составляющим - Ненецкий, Ханты-Мансийский и Ямало-Ненецкий автономные округа. В Чеченской Республике, наоборот, и производственные, и финансовые, и социальные показатели очень низкие.

Анализ структуры занятости по федеральным округам показал, что к 2015 г. наиболее эффективная структура занятости по Центральному федеральному округу сложилась в Белгородской и Московской областях, а также в г. Москва. Среди регионов Северо-Западного округа наиболее эффективной структурой за- 
нятости выделяется г. Санкт-Петербург, а в Приволжском - Республика Татарстан. В данных регионах показатели эффективности находятся либо на высоком, либо на среднем уровне. Худшая ситуация с точки зрения оценки эффективности структуры занятости в 2015 г. сложилась в Северо-Кавказском федеральном округе, где все регионы имели низкие значения показателей.

Важнейшими критериями результативности проводимых социальноэкономических реформ являются уровень безработицы, ее продолжительность, уровень занятости и уровень участия в рабочей силе.

Для анализа влияния «старого» сектора экономики на показатели занятости и безработицы была сформирована система статистически значимых и надежных уравнений регрессии для основных показателей рынка труда. Оценки коэффициентов показывают, что доля занятых в первичном секторе является значимым фактором, ухудшающим позиции региона на рынке труда. Увеличение доли занятых на предприятиях вторичного сектора сдерживает рост и продолжительность безработицы, что приводит к увеличению доли занятого населения.

Для определения зависимости показателей занятости и безработицы от развития «нового» сектора экономики были построены регрессионные модели. В числе значимых факторов для полного круга регионов оказались доли занятых на частных предприятиях и предприятиях сферы кредита и финансов. Для агропромышленных территорий уровень занятости отрицательно зависит от государственного сектора и положительно - от развития малых предприятий в сфере торговли. Уровень занятости в индустриальных регионах увеличивается при сокращении государственных предприятий и росте кредитно-финансовой сферы. Смешанные регионы характеризуются ростом уровня занятости при увеличении частных предприятий и предприятий смешанной формы собственности с участием иностранного капитала. Занятость в сервисных регионах также чутко реагирует на рост малых предприятий в сфере торговли и предприятий финансовой сферы.

Полученные в ходе исследования результаты эмпирического анализа доказывают, что унифицированный подход и усредненные оценки ситуации, происходящей на региональных рынках труда, являются малоэффективными. Существует необходимость одновременного учета и специализации региональных рынков труда по видам экономической деятельности и факторам, отражающим проведение экономической политики на уровне отдельных регионов.

Динамика основных относительных показателей, характеризующих рынок труда в Приволжском федеральном округе, близка к динамике соответствующих показателей по стране в целом. Из этого следует, что рынок труда данного округа чутко реагирует на экономические изменения, происходящие в стране и может служить их отражением.

Для группировки регионов Приволжского федерального округа по индикаторам развития рынка труда использовались темпы роста за 2015 г. относительно 2005 г. по таким показателям, как уровень и продолжительность безработицы, уровень занятости и участие в рабочей силе.

Экономическая политика на уровне региона является существенным фактором, определяющим поведение основных показателей регионального рынка труда. Расширение частного сектора, малого и среднего бизнеса, развитие рынка 
B. С. Мхитарян, Т. В. Сарычева. Исследование структуры занятости по видам экономической деятельности в Российской Федерации

услуг и региональной инфраструктуры отражают развитие «нового» сектора экономики и воздействуют на региональный рынок труда различными путями: возрастает инвестиционная привлекательность региона, улучшаются его перспективы, расширяется сфера приложения труда, создаются дополнительные рабочие места, что способствует расширению рыночных поведенческих реакций. В результате проявляется эффект диверсификации региональной структуры рынка труда, который в работе был описан двухсекторной моделью, на основе анализа состояния и развития «старого» и «нового» секторов экономики [3].

Для группировки регионов Приволжского федерального округа по показателям, характеризующим расширение «нового» сектора, использовались темпы роста за 2015 г. относительно 2005 г. следующих показателей по 14 регионам:

$X_{5}$ - доля занятых на малых предприятиях, \%;

$X_{6}$ - доля занятых в торговле, \%;

$X_{7}$ - доля занятых в финансово-кредитной сфере, \%;

$X_{8}$ - доля занятых на предприятиях частной формы собственности, \%;

$X_{9}$ - доля занятых на предприятиях смешанной формы собственности с участием иностранного капитала, \%;

$X_{10}$ - доля занятых с высшим профессиональным образованием, \%;

$X_{11}$ - доля занятых со средним профессиональным образованием, \%;

$X_{12}$ — отношение среднедушевых денежных доходов населения к прожиточному минимуму, ед.

С помощью кластерного анализа регионы ПФО были разбиты на три качественно отличающиеся друг от друга типологические группы.

Влияние развитости институционального механизма управления системами занятости на динамику основных индикаторов рынка труда регионов оценивалось путем сопоставления результатов классификаций, проведенных на основе показателей развития «нового» сектора, и индикаторов рынка труда (табл. 2).

Таблица 2

Сопоставление результатов классификации регионов ПФО

по показателям развития «нового» сектора и основным индикаторам рынка труда регионов

\begin{tabular}{|c|c|c|c|c|}
\hline \multirow{2}{*}{\multicolumn{2}{|c|}{$\begin{array}{c}\text { Сопоставление } \\
\text { результатов } \\
\text { классификации } \\
\end{array}$}} & \multicolumn{3}{|c|}{ Классификация регионов по развитию «нового» сектора } \\
\hline & & \multirow{2}{*}{$\begin{array}{c}\begin{array}{c}\text { Институциональные } \\
\text { регионы }\end{array} \\
\text { Республика Татарстан }\end{array}$} & \multirow{2}{*}{$\begin{array}{c}\text { Инновационные } \\
\text { регионы } \\
-\end{array}$} & \multirow{2}{*}{$\begin{array}{l}\text { Инерционные регионы } \\
\text { Чувашская Республика, } \\
\text { Республика Мордовия }\end{array}$} \\
\hline 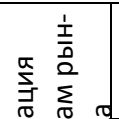 & $\begin{array}{l}\text { Регионы - } \\
\text { локомотивы } \\
\text { роста }\end{array}$ & & & \\
\hline 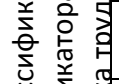 & $\begin{array}{l}\text { Опорные } \\
\text { регионы }\end{array}$ & $\begin{array}{l}\text { Нижегородская об- } \\
\text { ласть }\end{array}$ & - & $\begin{array}{l}\text { Пензенская область, } \\
\text { Республика Марий Эл }\end{array}$ \\
\hline 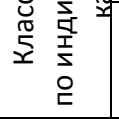 & $\begin{array}{c}\text { Отстающие } \\
\text { регионы }\end{array}$ & $\begin{array}{c}\text { Ульяновская область, } \\
\text { Республика Башкорто- } \\
\text { стан }\end{array}$ & $\begin{array}{l}\text { Удмуртская Респуб- } \\
\text { лика, Кировская об- } \\
\text { ласть, Пермский край }\end{array}$ & $\begin{array}{c}\text { Оренбургская область, } \\
\text { Саратовская область, } \\
\text { Самарская область }\end{array}$ \\
\hline
\end{tabular}

Результаты сопоставления свидетельствуют об относительной согласованности процессов, происходящих на региональных уровнях, и, следовательно, об инерционности, сохраняющейся на региональных рынках труда. Однако следует 
отметить, что регионы с более высокой долей «нового» сектора в структуре занятости имеют лучшие перспективы социально-экономического развития, чем регионы со сравнительно низкой долей «нового» сектора. Ульяновская область, Республика Башкортостан благодаря взвешенной экономической политике уже в скором времени смогут покинуть группу отстающих регионов. То же самое касается и инновационных регионов Удмуртской Республики, Кировской области, Пермского края, которые благодаря высокому уровню взаимодействия между производством и наукой имеют возможность существенно увеличить производительность труда в секторах экономики, которые вносят максимальный вклад в объем валового регионального продукта, что будет способствовать росту эффективности функционирования рынка труда. Республика Марий Эл и Пензенская область, наоборот, пока еще находятся в группе опорных регионов. В случае правительственного невмешательства в трансформационные процессы в данных регионах развитие региональных рынков труда может серьезно замедлиться, что, в свою очередь, повлечет за собой отставание и в уровне социальноэкономического развития регионов [10].

Предложенная классификация регионов Приволжского федерального округа создала адекватную базу для анализа групп территорий и позволила выделить показатели, которые могут быть положены в основу формирования долгосрочной стратегии социально-экономического развития, способной региональную политику перевести на новый качественный уровень.

Важнейшими критериями результативности проводимых социальноэкономических реформ следует считать уровень безработицы и ее продолжительность, уровень занятости и участия населения в рабочей силе. Они отражают способность к адаптации и приспособленность структуры занятости и экономики региона в целом к новым рыночным отношениям.

Для того чтобы судить о состоянии сферы занятости и безработицы в регионах Приволжского федерального округа (ПФО) и более четко установить региональные факторы роста данных показателей, был проведен анализ влияния факторов на развитие региональных рынков труда, основанный на построении регрессионных моделей.

Анализ проводился как по всем регионам в совокупности, так и в отдельности для агропромышленных, индустриальных, смешанных и сервисных. Информационную базу исследования составили пространственно-временные данные за 2005-2015 гг. по 14 регионам ПФО. В качестве основных индикаторов рынка труда выступали следующие показатели:

$y_{I}$ - уровень безработицы, \%;

$y_{2}$ - продолжительность безработицы, мес.;

$y_{3}$ - уровень занятости, \%;

$y_{4}$ - уровень участия в рабочей силе, $\%$.

Для анализа влияния «старого» сектора экономики на показатели занятости и безработицы были выбраны следующие объясняющие переменные:

$X_{1}$ - доля занятых в первичном секторе экономики, \%;

$X_{2}$ - доля занятых во вторичном секторе экономики, \%;

$X_{3}$ — площадь сельскохозяйственных угодий в \% от общей площади, км²;

$X_{4}$ - плотность населения, чел/км ${ }^{2}$. 
B. С. Мхитарян, Т. В. Сарычева. Исследование структуры занятости по видам экономической деятельности в Российской Федерации

Последние два показателя были введены для того, чтобы различия в площади территорий регионов не привели к искажению результатов моделирования.

Рыночная экономика обладает определенной инертностью, поэтому для исключения эффекта эндогенности использовалась лаговая структура регрессионных уравнений $(\tau=0 ; 1 ; 2)$. Первоначально регрессионные модели включали все объясняющие переменные. Методом пошагового исключения незначимых по $t$ критерию переменных были построены статистически значимые и надежные уравнения регрессии (табл. 3).

Таблица 3

Регрессионные уравнения, характеризующие индикаторы рынка труда (по пространственно-временным данным по регионам ПФО за 2005-2015 гг.)

\begin{tabular}{|c|c|c|}
\hline $\begin{array}{l}\text { Индикаторы } \\
\text { рынка труда }\end{array}$ & Регрессионные уравнения & $\begin{array}{c}\text { Статистические } \\
\text { характеристики } \\
\text { уравнения }\end{array}$ \\
\hline $\begin{array}{c}\text { Уровень } \\
\text { безработи- } \\
\text { цы } \\
\end{array}$ & $\begin{array}{cccc}\hat{y}_{1 i t}= & 21,1-0,43 x_{2}{ }_{i t-1}-0,07 x_{3 i t}+0,04 x_{4} \\
t \text {-cmam.: } & (-5,4) & (-6,4)\end{array}$ & $\begin{array}{l}R^{2}=0,69 ; F=69,7 \\
D W=2,3 ; \text { S.E. }=1,5\end{array}$ \\
\hline $\begin{array}{c}\text { Продолжи- } \\
\text { тельность } \\
\text { безработи- } \\
\text { цы }\end{array}$ & $\begin{array}{c}\hat{y}_{2 i t}=2,7+0,1 x_{1 i t-1}+0,1 x_{2 i t-1} \\
t \text {-cmam.: } \quad(3,9) \quad(2,8)\end{array}$ & $\begin{array}{l}R^{2}=0,74 ; F=135,2 ; \\
D W=1,8 ; \text { S.E. }=0,9\end{array}$ \\
\hline $\begin{array}{l}\text { Уровень } \\
\text { занятости }\end{array}$ & $\begin{aligned} & \hat{y}_{3 i t}=108,9-0,1 x_{1 i t-1}+0,7 x_{2 i t-1}+0,01 x_{3 i t} \\
& t \text {-cmam.: }(-2,9)\end{aligned}$ & $\begin{array}{l}R^{2}=0,91 ; F=3168 \\
D W=2,1 ; \text { S.E. }=0,6\end{array}$ \\
\hline $\begin{array}{l}\text { Уровень } \\
\text { участия } \\
\text { в рабочей } \\
\text { силе }\end{array}$ & $\begin{array}{lll}\hat{y}_{4 i t}=72,9-0,1 x_{1 i t-1}+0,1 x_{2 i t-1}+0,01 x_{3 i t}+0,04 x_{4 i t} & \\
t \text {-cmam.: } & (-2,9) & (2,8)\end{array}$ & $\begin{array}{l}R^{2}=0,79 ; F=87,5 \\
D W=2,2 ; \text { S.E. }=1,1\end{array}$ \\
\hline
\end{tabular}

Анализ коэффициентов полученных уравнений позволил сделать вывод о том, что доля занятых в первичном секторе является значимым отрицательным фактором, ухудшающим позиции региона на рынке труда. Ее увеличение приводит к снижению уровня занятости как в целом по совокупности всех регионов ПФО, так и в каждой типологической группе. Размеры первичного сектора оказывают негативное влияние на региональные рынки труда. Развитие вторичного сектора, наоборот, существенно снижает напряженность на рынках труда в регионах.

Рост доли занятых в первичном секторе экономики $\left(x_{l}\right)$ на $1 \%$ приводит к снижению уровней занятости и участия в рабочей силе на $0,1 \%$, увеличивает уровень безработицы и ее продолжительность на $0,4 \%$ и 0,1 мес. соответственно. Увеличение доли занятых на предприятиях вторичного сектора $\left(x_{2}\right)$ на $1 \%$ сокращает рост безработицы на $0,07 \%$, способствует увеличению доли занятого населения на $0,7 \%$. Доказательством данных фактов являются статистическая значимость и знаки коэффициентов при соответствующих переменных в каждом из регрессионных уравнений, характеризующих индикаторы рынка труда.

Полученные в ходе исследования региональных рынков труда результаты эмпирического анализа доказывают, что унифицированный подход и усредненные оценки ситуации на региональных рынках труда малоэффективны. Для реализации основных направлений экономических реформ и создания эффективной структуры 
занятости необходимы учет и специализация региональных рынков труда по секторам экономики и факторов диверсификации экономики на уровне региона [9].

Реализация эффективной политики, направленной на развитие рынка труда и расширение сферы занятости отдельного региона, невозможна без определения базовых конкурентоспособных видов экономической деятельности. В работе под конкурентоспособностью вида экономической деятельности понималось наличие сравнительного преимущества по отношению к другим видам деятельности региона. Вид экономической деятельности обладает сравнительным преимуществом в том случае, если он является привлекательным для работника с точки зрения заработной платы и условий труда.

Для оценки конкурентоспособности видов экономической деятельности Республики Марий Эл использовался интегральный индекс конкурентоспособности, рассчитанный как средние геометрические значения произведений показателей функциональности, системности, проактивности и органичности, отражающие сравнительные преимущества видов экономической деятельности. Исходными данными для их расчета выступала статистическая информация за период 20052015 гг.:

$x_{1}$ - доля оборота организаций вида экономической деятельности в общем обороте организаций РМЭ, \% (показатель функциональности);

$x_{2}$ - валовая добавленная стоимость организаций на 1000 человек, занятых по видам экономической деятельности республики, соотнесенная с совокупной валовой добавленной стоимостью организаций на 1000 человек, занятых в экономике РМЭ, ед. (показатель системности);

$x_{3}$ - доля инвестиций в основной капитал по видам экономической деятельности в общем объеме инвестиций РМЭ, \% (показатель проактивности);

$x_{4}$ - доля предприятий и организаций по видам экономической деятельности в общем числе предприятий и организаций РМЭ, \% (показатель органичности).

Анализ интегрального индекса конкурентоспособности показал, что явным лидером Республики Марий Эл за анализируемый период времени являлся один вид экономической деятельности - обрабатывающие производства. Самые низкие значения данного показателя характеризовали гостиницы, рестораны и здравоохранение. Полученные результаты повышают объективность и обоснованность инвестиционной политики, направленной на повышение конкурентоспособности видов деятельности, которая составляет основу экономики региона, и позволяют добиться экономического и социального эффектов [8].

Рынок труда каждого региона страны в той или иной степени существует в условиях гендерной асимметрии.

Для анализа количественных изменений в гендерной занятости была проведена группировка видов экономической деятельности в зависимости от тенденций, характеризующих направления изменений в численности работников по полу, относительно крайних периодов анализируемого временного интервала (2015 г. относительно 2005 г.). В качестве информационной базы выступали данные о численности занятых по видам деятельности в гендерном разрезе, полученные по материалам выборочных обследований по проблемам занятости.

Анализ количественных изменений в гендерной занятости проводился методом группировки видов экономической деятельности в зависимости от основныХ 
B. С. Мхитарян, Т. В. Сарычева. Исследование структуры занятости по видам экономической деятельности в Российской Федерации

тенденций изменения численности занятых мужчин и женщин. Это позволило разделить все виды экономической деятельности на четыре группы (табл. 4).

Таблица 4

Группировка видов экономической деятельности РМЭ по показателям динамики гендерной занятости, 2015-2005 гг.

\begin{tabular}{|c|c|c|c|c|}
\hline \multirow[t]{2}{*}{$\begin{array}{c}\text { № } \\
\text { группы }\end{array}$} & \multirow[t]{2}{*}{$\begin{array}{c}\text { Тенденции гендерной } \\
\text { занятости }\end{array}$} & \multirow[t]{2}{*}{$\begin{array}{c}\text { Виды экономической } \\
\text { деятельности }\end{array}$} & \multicolumn{2}{|c|}{$\begin{array}{c}\text { Темп } \\
\text { роста/сокращения } \\
\text { занятости, \% }\end{array}$} \\
\hline & & & муж. & жен. \\
\hline \multirow{3}{*}{1} & \multirow{3}{*}{$\begin{array}{l}\text { сокращение численно- } \\
\text { сти занятых обоего пола }\end{array}$} & Сельское хозяйство & 53,1 & 49,7 \\
\hline & & Рыболовство и рыбоводство & 25,0 & 0,0 \\
\hline & & Образование & 49,6 & 82,8 \\
\hline \multirow{5}{*}{2} & \multirow{5}{*}{$\begin{array}{c}\text { рост численности занятых } \\
\text { обоего пола }\end{array}$} & $\begin{array}{l}\text { Обрабатывающие } \\
\text { производства }\end{array}$ & 121,2 & 137,9 \\
\hline & & Транспорт и связь & 104,9 & 106,1 \\
\hline & & Финансовая деятельность & 145,5 & 127,3 \\
\hline & & Государственное управление & 106,0 & 138,2 \\
\hline & & $\begin{array}{c}\text { Предоставление прочих } \\
\text { коммунальных, социальных } \\
\text { и персональных услуг } \\
\end{array}$ & 158,3 & 131,2 \\
\hline \multirow{3}{*}{3} & \multirow{3}{*}{$\begin{array}{c}\text { рост численности занятых муж- } \\
\text { чин, сокращение численности } \\
\text { занятых женщин }\end{array}$} & Строительство & 168,6 & 70,5 \\
\hline & & Гостиницы и рестораны & 233,3 & 90,9 \\
\hline & & $\begin{array}{c}\text { Здравоохранение и предо- } \\
\text { ставление социальных услуг }\end{array}$ & 125,9 & 79,4 \\
\hline \multirow{4}{*}{4} & \multirow{4}{*}{$\begin{array}{c}\text { сокращение численности заня- } \\
\text { тых мужчин, рост численности } \\
\text { занятых женщин }\end{array}$} & $\begin{array}{c}\text { Добыча } \\
\text { полезных ископаемых }\end{array}$ & 33,3 & 100,0 \\
\hline & & $\begin{array}{c}\text { Производство } \\
\text { и распределение электроэнер- } \\
\text { гии, газа и воды }\end{array}$ & 88,4 & 157,1 \\
\hline & & $\begin{array}{c}\text { Оптовая и розничная торгов- } \\
\text { ля }\end{array}$ & 81,3 & 100,3 \\
\hline & & $\begin{array}{c}\text { Операции с недвижимым } \\
\text { имуществом }\end{array}$ & 81,6 & 101,8 \\
\hline
\end{tabular}

Прежде всего выделяются два вида экономической деятельности: сельское хозяйство, охота и лесное хозяйство и обрабатывающие производства. Изменения численности занятых здесь имели не только самый массовый, но и разнонаправленный характер. Численность занятых в сельском хозяйстве, охоте и лесном хозяйстве мужчин сократилась на 46,9\%, женщин - на 51,3\%, что явилось следствием серьезного сокращения численности сельского населения в трудоспособном возрасте: если в 2005 г. в сельской местности проживало 292,6 тыс. человек в трудоспособном возрасте, то к концу 2015 г. данная категория граждан республики составила всего 253,7 тыс. человек. В обрабатывающих производствах, наоборот, наблюдался значительный приток женских кадров, который по интенсивности темпов роста превышал рост мужских. Однако нельзя считать, что женщины «вытеснили» мужчин из этих сфер деятельности. Все мужские рабочие места сохранились, но в борьбе за новые рабочие места мужчины явно уступали женщи- 
нам. В связи с чем вывод о гендерных особенностях кадровых процессов может быть следующим: в развивающихся сферах деятельности темп роста численности женщин значительно выше, чем рост численности мужских кадров.

Для анализа качественных сдвигов в гендерной структуре виды экономической деятельности были разделены на три группы: преимущественно мужские, преимущественно женские и интегрированные. Типичные для мужчин и женщин виды экономической деятельности определялись в соответствии с методикой Ф. Блау. Группировка видов экономической деятельности проводилась на основании значения уровня занятости женщин. Вид экономической деятельности был отнесен к «преимущественно женским», если $p_{i}>(P+10)$; вид экономической деятельности признавался «преимущественно мужским», если $p_{i}<(P+10)$, где $p_{i}$ — доля женщин в общем числе занятых в данном виде деятельности, $P-$ доля женщин в общей численности занятых в региональной экономике. Остальные виды экономической деятельности считались «интегрированными».

Наивысшая концентрация женской рабочей силы на протяжении 2005-2015 гг. характеризовала такие виды деятельности, как оптовая и розничная торговля (здесь доля занятых женщин в среднем составляла $68,1 \%$ ), гостиницы и рестораны (самая «феминизируемая» сфера деятельности, удельный вес занятых мужчин в которой не превышал 18,5\%); финансовая деятельность (с 2009 по 2015 г. удельный вес женщин, занятых в этом виде деятельности, снизился с 87,2 до $72,4)$, образование (в этой сфере деятельности женщины составляют около $3 / 4$ общего числа занятых), здравоохранение и предоставление социальных услуг (удельный вес мужчин в данном виде деятельности ни разу за одиннадцать последних лет не превышал отметку 20\%) и предоставление коммунальных, социальных и персональных услуг (вид экономической деятельности, который максимально из всех «преимущественно женских» видов деятельности приближался к интегрированным, так как удельный вес занятых здесь женщин в 2011 г. составил $60,0 \%$ ) (рис. 6).

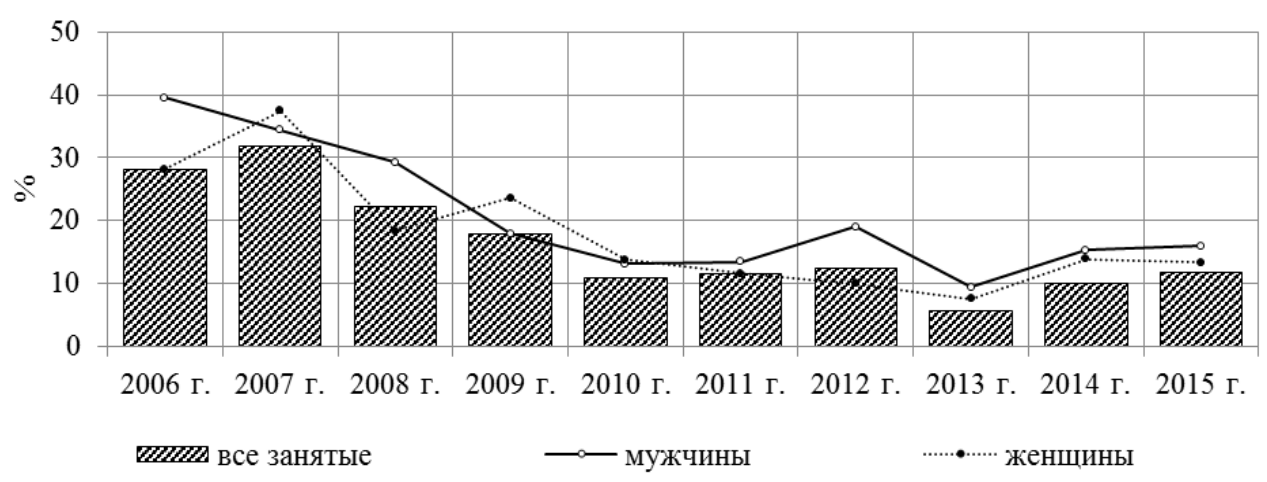

Рис. 6. Динамика значений индексов структурных сдвигов в занятости по видам экономической деятельности РМЭ, \%, 2006-2015 гг.

Анализ изменений в структурах занятости по видам экономической деятельности позволил сделать следующие основные выводы: структурные изменения в занятости по экономике в целом сопровождаются более крупными изменениями в 
B. С. Мхитарян, Т. В. Сарычева. Исследование структуры занятости по видам экономической деятельности в Российской Федерации

гендерной структуре занятости, причем мужская занятость в большинстве периодов отличается более масштабным уровнем изменения структуры. В последние годы интенсивность структурных сдвигов сократилась, а структура занятости относительно стабилизировалась, изменения в структуре совокупной, мужской и женской занятости стали сопоставимыми, то есть размах значений структурных сдвигов занятости для мужчин и женщин существенно уменьшился [5].

Трансформации, происходящие в структуре занятости РМЭ, не связаны с вытеснением женщин мужчинами из сферы экономической деятельности в домашнюю. Переформирование видов экономической деятельности происходит преимущественно благодаря мужчинам, которые переходят из одних видов деятельности в другие, а сокращение доли женщин в отдельных сферах обусловлено их естественной убылью.

Асимметрия в гендерной структуре занятости неразрывно связана с региональными различиями в величине заработной платы по видам экономической деятельности. Чем больше доля женщин в составе занятых в виде экономической деятельности, тем ниже соотношение величины заработной платы в том же виде экономической деятельности к средней величине заработной платы в региональной экономике. То есть «преимущественно мужские» виды экономической деятельности с течением времени становятся более высокодоходными, а «преимущественно женские» - низкодоходными. Если же в связи с благоприятной экономической конъюнктурой на региональном рынке труда какой-либо вид деятельности начинает быть более доходным, то туда сразу перенаправляются потоки мужской рабочей силы, благодаря тому, что, во-первых, работодатели большее предпочтение отдают мужчинам, а во-вторых, более доходные виды экономической деятельности предъявляют гораздо более высокие требования к трудовым нагрузкам, с которыми женщины ввиду большого объема семейных обязанностей не всегда способны справиться.

При разработке и проведении региональной социально-экономической политики важными являются согласование основных тенденций развития регионального рынка труда, обоснование адекватного инструментария анализа спроса на рабочую силу, позволяющего описывать взаимосвязь структуры рынка труда и занятости и факторов, определяющих их динамику.

Численность занятого населения количественно отражает совокупный спрос экономики на труд. Его структура по видам экономической деятельности определяется, прежде всего, объемами производства и инвестиций в основной капитал. Предложение труда отражает готовность работников продавать услуги своего труда за существующее на рынке вознаграждение. На величину совокупного предложения труда и его структуру непосредственное влияние оказывает политика в области заработной платы. Рассогласование спроса и предложения приводит к безработице или дефициту рабочей силы. Эти явления сосуществуют на современном рынке труда любого региона [1].

В качестве инструментария, позволяющего провести содержательный анализ влияния основных факторов на занятость по видам экономической деятельности, был использован регрессионный анализ. Информационной базой послужили пространственно-временные данные с 2005 по 2015 г. по видам экономической деятельности. Два вида деятельности (рыболовство и рыбоводство, а также до- 
быча полезных ископаемых) были исключены из рассмотрения ввиду незначительного числа занятых: совокупная величина данного показателя для этих сфер деятельности составляет всего $0,4 \%$ общего числа работников предприятий и организаций республики.

В качестве значений результативного признака $\left(y_{i t}\right)$ выступали данные о среднегодовой численности работников предприятий и организаций по видам деятельности $(i)$ в тыс. человек в период времени $t$. В качестве факторных признаков использовались следующие показатели:

$x_{1_{i t}}$ - отношения величины среднемесячной начисленной заработной платы работников в $i$-м виде экономической деятельности к средней по Республике Марий Эл в момент времени $t$,

$x_{2_{i t}}$ — число предприятий и организаций государственной формы собственности в $i$-м виде экономической деятельности в момент времени $t$, ед.;

$x_{3_{i t}}$ - число предприятий и организаций частной формы собственности в $i$-м виде экономической деятельности в момент времени $t$, тыс. ед.;

$x_{4_{i t}}$ - производительность труда в $i$-м виде экономической деятельности в момент времени $t$, млн руб/чел.;

$x_{5_{i t}}$ - фондовооруженность в $i$-м виде экономической деятельности в момент времени $t$, млн руб/чел.;

$x_{6_{i t}}$ - степень износа основных фондов в $i$-м виде экономической деятельности в момент времени $t, \%$;

$x_{7_{i t}}$ - индекс физического объема инвестиций в основной капитал $i$-го вида экономической деятельности в момент времени $t, \%$.

Сформированная информационная база содержала 143 наблюдения, пропущенных данных нет, панель сбалансирована. Наилучший результат аппроксимации показала модель со случайными индивидуальными эффектами, для оценивания коэффициентов которой использовался обобщенный метод наименьших квадратов. Тест множителей Лагранжа позволил определить преимущество данной модели перед моделью сквозной регрессии, так как значение $L M=657,61$ статистически значимо. Проведенный тест Хаусмана позволил сделать выбор также в пользу модели со случайными эффектами относительно модели с фиксированными эффектами. Удаление незначимого по $z$-критерию факторных признаков $x_{6}$ и $x_{7}$, характеризующих соответственно степень износа основных фондов и индекс физического объема инвестиций в основной капитал по видам деятельности, позволило несколько упростить модель, в которой в результате остались пять независимых переменных:

$$
\hat{y}_{i t}=13,001-2,015 x_{1_{i t}}+0,018 x_{2_{i t}}+0,005 x_{3_{i t}}-0,002 x_{4_{i t}}-0,001 x_{5_{i t}}
$$

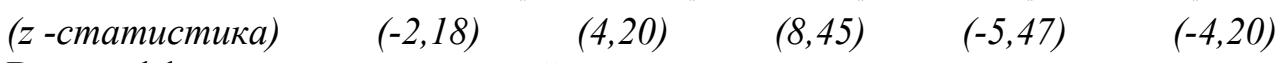

Все коэффициенты в полученной модели статистически значимы при уровне значимости $\alpha<0,05$. Значимость уравнения регрессии в целом обусловливается высоким значением статистики Вальда (Wald chi $2=176,72)$ и уровнем значимости, не превышающим 0,05. 
B. С. Мхитарян, Т. В. Сарычева. Исследование структуры занятости по видам экономической деятельности в Российской Федерации

Интерпретируя влияние показателей на занятость по видам экономической деятельности, можно видеть, что снижение уровня заработной платы $\left(x_{1}\right)$ приводит к росту занятости. Величина средней номинальной заработной платы в РМЭ существенно отличается от среднероссийской и окружной. В 2015 г. их соотношения составили соответственно 64,5 и 85,6\%, в то время как официальный прожиточный минимум в регионе сближается с общероссийским и окружным: в 2015 г. он составил 83,2\% от аналогичного по России и 94,4\% - по ПФО. Такой уровень заработной платы стимулирует быть занятыми всех взрослых членов семьи (порой даже одновременно на нескольких рабочих местах), а в наиболее бедных семьях - и подростков. Заниженная цена рабочей силы стимулирует к поиску дополнительных доходов, при этом складывается негативное отношение к легализованной и добросовестной трудовой деятельности, подрывается доверие к государственной власти, неспособной решить проблемы достойного обеспечения населения доходами.

С другой стороны, на величину заработной платы оказывает влияние существующее соотношение спроса и предложения на рабочую силу. В экономике Республики Марий Эл спрос на рабочую силу гораздо ниже, чем имеющиеся предложения. Рынок труда региона функционирует в условиях конкуренции работников между собой за получение рабочего места, что приводит к тенденции занижения цены на рабочую силу и созданию условий для установления размеров оплаты труда, которые значительно ниже стоимости рабочей силы.

Увеличению численности занятого населения в Республике Марий Эл будут способствовать меры, направленные на государственную поддержку крупных частных предприятий $\left(x_{3}\right)$, которые играют существенную роль в продвижении экономических интересов региона.

Заключение. Проведенный анализ занятости населения России по видам экономической деятельности на макро-, мезо- и микроуровне экономической иерархии позволил получить комплексное представление о процессах, протекающих на рынке труда страны и ее отдельных регионов. Предложенные подходы направлены на совершенствование статистического учета занятости по видам экономической деятельности, выступающего основой для построения системы сбора и обработки официальной статистической информации для обеспечения актуальности, своевременности, надежности и региональной сопоставимости данных о структуре занятости по видам деятельности и ее эффективности. Результаты исследования призваны обеспечить оперативность, качество и достоверность информационно-аналитического обеспечения при принятии эффективных управленческих решений, направленных на развитие сферы занятости, повышения конкурентоспособности и устойчивости развития российской экономики.

\section{Литература}

1. Архипова М. Ю. Анализ региональной дифференциации малого инновационного бизнеса в России // Вестник НГУЭУ. 2015. № 4. С. 54-65.

2. Бычкова С. Г. Проблемы и возможности статистической оценки неравенства и бедности в Российской Федерации и ее регионах региона // Вестник университета (Государственный университет управления). 2016. № 1. С. 226-232.

3. Дуброва Т. А. Тенденции и региональная неоднородность развития малого предпринимательства в России // Федерализм. 2016. № 1 (81). С. 185-200. 
4. Зарова Е. В. Показатели производительности труда в системе индикаторов устойчивого развития // Вопросы статистики. 2017. № 12. С. 16-24.

5. Кучмаева О. В., Ростовская Т. К., Смакотина Н. Л. Образовательный потенциал российской молодежи: гендерный анализ / // Alma mater (Вестник высшей школы). 2017. № 7. C. $28-32$.

6. Матраева Л. В., Башина О. Э., Васютина Е. С. Анализ трансформационных процессов на российском рынке труда: вызовы и последствия // Вопросы статистики. 2017. № 11. С. $35-43$.

7. Мхитарян В. С., Сарычева Т. В. Прогнозирование занятости населения в Российской Федерации по видам экономической деятельности // Вопросы статистики. 2017. № 3. С. $18-29$.

8. Садовникова Н. А., Моисейкина Л. Г., Леденева И. К. Анализ инвестиционной привлекательности субъектов Российской Федерации // Инновации и инвестиции. 2016. № 10. С. 204-210.

9. Сажин Ю. В., Подольная Н. Н. Исследование макроэкономических взаимосвязей в развитии региональной экономики (на основе данных региональных счетов) // Региональная экономика: теория и практика. 2011. № 20. С. 24-28.

10. Bakumenko L. P., Kostromina E.V. Analysis of Demo-Economic Processes in Volga Federal District // International Journal of Economic Perspectives. 2016. T. 10, № 2. P. $212-$ 220.

\section{A STUDY OF THE EMPLOYMENT COMPOSITION BY TYPES OF ECONOMIC ACTIVITY IN THE RUSSIAN FEDERATION}

\section{Vladimir S. Mkhitaryan}

Dr. Sci. (Econ.), Prof.,

National Research University «Higher School of Economics»

20 Myasnitskaya St., Moscow 101000, Russia

E-mail: vmkhitarian@hse.ru

\section{Tatyana V. Sarycheva}

Cand. Sci. (Econ.), A/Prof.,

Mari State University

1 Lenina Square, Yoshkar-Ola 424000, Russia

E-mail: tvdolmatova@bk.ru

The employment patterns corresponding to the chosen reform course provides the stable development of the economy. The composition of employment is a key aspect in the analysis of the existing labor market and an integral part of the whole complex of correlations of economic growth in the country and its regions. Successful employment management at federal and regional levels requires the development of statistical tools to reveal the quantitative patterns of correlation of labor market indicators. The use of such tools will improve the efficiency of the labor market and the validity of employment decisions, taking into account the types of economic activity. The article proposes the statistical tools based on the use of methods for multidimensional statistical analysis, econometric modeling and forecasting, which allows carrying out an integrated statistical analysis of employment by type of economic activity at federal and regional levels.

Keywords: composition of employment; types of economic activity; econometric modeling; econometric forecasting. 